\title{
An Exploration of User-Generated Wireless Broadband Infrastructures in Digital Cities
}

Catherine A. Middleton

Amelia Bryne

Accepted Author Manuscript. This paper will be published as Middleton, C. A., \& Bryne, A. An Exploration of User-Generated Wireless Broadband Infrastructures in Digital Cities. Telematics \& Infomatics, doi: 10.1016/j.tele.2010.08.003.

\begin{abstract}
This paper examines the broadband connectivity options available in digital cities. It offers an overview of services provided by commercial operators, the public sector and by citizens themselves, arguing that shortcomings in existing fixed broadband and commercial mobile broadband services provide an opportunity for citizens to share their own wireless broadband connections. It explores Wi-Fi hotspot provider FON's approach to extending mobile broadband infrastructure by enabling shared connections within communities. The paper outlines some reasons why this specific user-generated approach to infrastructure provision has been unable to deliver highly robust broadband infrastructure, and discusses ways in which users and the public sector can be involved in developing new mobile infrastructures that will meet citizens' needs.
\end{abstract}

\section{Introduction}

This paper discusses the provision of broadband infrastructure in digital cities. In Section 2, it identifies three categories of infrastructure providers, and explores whether their fixed and mobile broadband offerings meet the connectivity needs of digital citizens. Noting that fixed broadband services are currently more likely than mobile broadband services to deliver affordable, high quality and reliable connectivity, in Section 3 the paper investigates a usergenerated approach for providing wireless broadband connectivity. The demand for ubiquitous network access is increasing as citizens embrace mobility (Sandvine, 2010), using netbooks, laptops, tablet and smart phones to connect to information and government services, entertainment content and each other while moving around cities. User-generated infrastructure could help increase network availability, for example by using wireless networking technologies 
to extend the reach of individuals' broadband connections. In Section 4 the paper describes how the FON community has supplemented broadband connectivity in digital cities by facilitating sharing of Wi-Fi hotspots. Section 5 notes the various challenges that arise in relying upon individuals to develop good broadband infrastructure. The paper concludes with discussion of why user-generated infrastructure is unlikely to provide a foundation for connectivity in digital cities (Section 6). Opportunities for municipalities or communities to develop wired and wireless networks to provide high quality, reliable infrastructure, possibly through a hybrid approach, are noted, and closing remarks are provided in Section 7.

\section{Infrastructure for Digital Cities}

"Digital city" projects are the most recent in a long line of efforts to use communication technologies to connect citizens to each other, to local governments, and to information repositories. The digital cities of the twenty-first century "build an arena in which people in regional communities can interact and share knowledge, experiences, and mutual interests" (Ishida, 2002, p. 76), and "create a seamless environment between local government and constituents" (Center for Digital Government, 2008, p. 2). Digital cities now offer a combination of "grassroots community and civic networks, municipal information and communication networks, city oriented commercial websites, virtual communities, and social ICT experiments in neighborhoods" (Van Den Besselaar, 2005, p. 4). To make use of these services or participate in these civic networks, citizens need broadband Internet access.

Over the mid-1990s and the early-2000s, residential Internet access became common in households. As users switched from dial-up to broadband access (Rainie and Horrigan, 2005; Horrigan, 2009), the location for digital engagement with government and community remained in the home. Since the mid-2000s, interaction with the digital city has moved beyond individuals' homes, into community spaces and other locations, indoor or outdoor, wherever network access is available. This expanded footprint of the digital city has been enabled by wireless networks, based on Wi-Fi, WiMAX and 3/3.5/4G cellular technologies (Lehr and McKnight, 2003; Johnston and Aghvami, 2007; Lemstra and Hayes, 2009; Otsuka, 2009, describe these technologies), along with growing use of laptop and netbook computers, smart phones and other mobile devices (e.g. ebook readers, Internet tablets).

The unwiring of access can change the ways that citizens engage with digital city 
environments, allowing interaction from places and at times that are convenient to them. As more citizens roam their physical cities with connected network devices in hand, their expectations move beyond visions of digital cities as specific, government-led projects toward visions of digital cities as places that offer seamless integration of digital technologies, content and services for any purpose. Cities are becoming digital spaces, where connectivity supports citizens' interactions not just with local governments and local residents, but with content, applications, services and people located anywhere. Indeed, the National Broadband Plan in the US notes that "broadband is essential to opportunity and citizenship" (Federal Communications Commission, 2010, p. 5), and accessible, affordable, reliable infrastructure is an essential foundation for digital cities.

Many countries are developing strategies to improve their broadband infrastructures (e.g. Department for Culture Media and Sport and Department for Business Innovation and Skills, 2009; Industry Canada, 2009; Prime Minister of Australia, 2009; Federal Communications Commission, 2010). To date however, the development and uptake of wireless infrastructure that supports connectivity as people move around cities has tended to lag that of fixed broadband, raising questions about how wireless infrastructures might be improved to better meet the needs of digital citizens. An overview and assessment of the fixed and mobile broadband infrastructures available in digital cities $^{1}$ is provided below.

\subsection{Broadband Infrastructure in Digital Cities}

Fixed broadband provides connectivity to people in specific locations like their homes. Fixed broadband subscriptions may be shared (e.g. individuals can add a wireless router to a fixed broadband connection to allow network access within that fixed premise), but service is delivered to a specific location and cannot be used elsewhere. Individuals generally have only one fixed broadband provider. Nomadic broadband offers connectivity to individuals in a variety of locations (Kleinrock, 2001). For instance, an individual can access a nomadic broadband service in a café, a hotel, or in a public place like a park or a library. Individuals may use

\footnotetext{
${ }^{1}$ The broadband infrastructures described here are typical of those available in cities in western Europe, the United States, Canada, Australia, New Zealand, Japan, Hong Kong, Singapore and South Korea. As measured by the OECD (http://www.oecd.org/sti/ict/broadband), there are differences in pricing and average network speeds across these countries, but the types of services described here can be found in many urban areas. Some types of connectivity (e.g. municipal or community wireless projects) are more common in some countries than in others. These services are less widely available in rural or remote areas of these countries.
} 
multiple nomadic broadband providers to support their connectivity needs as they roam from one location to another. Mobile broadband services allow users connectivity while they are moving, for instance while travelling in a vehicle or airplane. The distinction between nomadic and mobile broadband is important in terms of functionality for users (WiMAX Forum, 2005) but in this paper nomadic and mobile broadband are considered together. As used here, the term mobile broadband encompasses any infrastructure that offers connectivity to citizens moving about digital cities.

Excluding the broadband services provided by employers and by educational institutions, three entities offer broadband services in digital cities: commercial organizations, municipal/ public sector organizations, and citizens (individually or in groups). As illustrated below, there is a multiplicity of choices for broadband connectivity in cities. Individuals may contract with one or more service providers to guarantee fixed and mobile broadband access, choose a combination of paid and free access, or rely entirely on free services for their fixed and mobile broadband access.

In OECD countries, the majority of subscribers get fixed broadband services from commercial (for-profit) providers, with $60 \%$ of services provided by DSL (digital subscriber line service using copper telephone lines), about $29 \%$ by cable and $9 \%$ with a fibre or LAN connection (Organisation for Economic Co-Operation and Development, 2010). Commercial broadband services do not meet everyone's needs, nor do they serve all locations, thus public sector service providers have emerged to extend affordable connectivity to citizens.

Although many municipal wireless projects failed (Middleton, 2007; Urbina, 2008), a few continue to deliver broadband services directly to homes (e.g. Wireless Minneapolis ${ }^{2}$ ). Municipalities and utility companies are taking an active role in the development of fibre-to-thehome (FTTH) networks (Fiber-to-the-Home Council and RVA LLC, 2009; Federal Communications Commission, 2010), providing very high quality broadband infrastructure (often bundled with telephone and television services) at affordable prices. Additionally, governments at all levels have funded the development of community access sites, which provide Internet access and training for everyone (see for example Rideout and Reddick, 2005).

Broadband infrastructure can also be developed by network users themselves. For a variety

${ }^{2} \mathrm{http}: / /$ www.usiwireless.com 
of reasons, individuals or groups of users may make broadband connections available to others. The most basic example of this is someone with a home wireless network, who by "generosity, ignorance or security failure" (Sandvig, 2004, p. 583) allows other people to use this connection as a Wi-Fi hotspot. Many people do not hesitate to make use of these 'found' points of connectivity, which offer free broadband access at fixed locations (Wong and Clement, 2007). Wi-Fi is used by local communities to provide connectivity to groups of users, for instance offering broadband to residents in an apartment building or within a small geographic location. ${ }^{3}$ Users are also building their own fibre-to-the-home projects. ${ }^{4}$ FTTH initiatives are quite rare, but like other user-led infrastructure projects, they allow users greater control over pricing and selection of services, by aggregating demand locally.

For broadband connectivity outside the home, commercial options include Internet cafés, WiFi hotspots, and mobile broadband services. Wi-Fi services are offered on a subscription basis or on a pay-per-use basis (e.g. by companies like Boingo or T-Mobile), require the user to find a Wi-Fi hotspot, and do not support mobility (i.e. a user cannot use hotspots to provide connectivity while travelling in a private vehicle). JiWire's 'Wi-Fi Finder' registry lists more than 300,000 free and fee-for-use hotspots around the world as of August 2010. In contrast, mobile broadband users access services using a portable modem that they can take anywhere they go, eliminating the need to physically go to a hotspot to get connectivity. Commercial $3 \mathrm{G} / 4 \mathrm{G}$ networks cover populous areas and allow connectivity from fixed locations or while in moving vehicles. Because of the flexibility of mobile broadband services, some users are choosing to replace or supplement their fixed broadband services with a mobile service. For instance, in Australia, close to $35 \%$ of all broadband subscriptions are for mobile services (Australian Bureau of Statistics, 2010). Mobile connections are also available on a pay-per-use basis on some airplanes, trains and buses.

From about 2004 to 2008, many municipalities, especially in the United States, planned or rolled out wireless infrastructures to provide connectivity in public places, providing broadband access to anyone moving around these municipalities (Shamp, 2004; Scott, et al., 2005;

\footnotetext{
${ }^{3}$ For example, the So Cal Free Net (http://socalfreenet.org) has been helping communities to develop local broadband access for many years.

${ }^{4}$ See Poulus (2010) for a description of owner-operated FTTH networks in the Netherlands.

${ }^{5} \mathrm{http}: / / \mathrm{v} 4$.jiwire.com/search-hotspot-locations.htm
} 
muniwireless.com, 2006; Powell and Shade, 2006; Vos, 2007; Vos, 2009; Hudson, 2010). Only a few of these initiatives are still going today, ${ }^{6}$ but as more municipalities consider the development of fibre networks (which could support wireless network overlays), it is possible that municipalities may become providers of mobile broadband services again in future.

'Community Wi-Fi' networks are built by community groups. Community wireless may serve fixed locations, but often these networks are designed to provide Internet access in public places to allow connectivity for users who are away from home. There are many operational community Wi-Fi networks, ${ }^{7}$ and they have been the subject of extensive research (Cho, 2008; Forlano, 2008; Middleton and Crow, 2008; Powell, 2008b; Powell and Meinrath, 2008).

Another source of connectivity for people who are moving around and/or between cities comes from the sanctioned use of individuals' personal Wi-Fi networks. The idea is that people who make their Wi-Fi connections available to community members can use other members' WiFi as they move around the community. Powered by individual broadband connections, this approach establishes a network of hotspots that are available to all members of the community, either within specific geographic locations ${ }^{8}$ or on a larger scale, ${ }^{9}$ with some sort of organization offering a federated structure to coordinate network membership and rules.

A final source of user-provided broadband infrastructure can support mobility, albeit on a small scale. Personal mobile hotspots (e.g. Novatel's MiFi or Huawei's E5) operate on 3G or 4G networks, and like other truly mobile broadband services can be used in moving vehicles as well as in fixed locations. Personal mobile hotspots can support several users, so by opening up a hotspot to users nearby (e.g. on a train or bus), an individual can offer mobile broadband access to others.

The options for accessing broadband infrastructures in digital cities (enabling use of digital

${ }^{6}$ e.g. Corpus Christi, TX (http://www.connectcc.com), Fredericton, Canada (http://www.fred-ezone.ca). Albuquerque, NM offers Wi-Fi around the city and on some city buses (http://www.cabq.gov/wifi)

7 e.g. Champaign-Urbana Community Wireless Network (http://www.cuwin.net/hotspots), Île Sans Fil (Montréal, http://www.ilesansfil.org), NYCWireless (http://www.nycwireless.net), Funkfeuer (http://www.funkfeuer.at/index.php?id=42\&L=1), Wireless Toronto (http://wirelesstoronto.ca).

${ }^{8}$ This was the approach taken by Wireless Nomad to make broadband available to members within Toronto (see http://web.archive.org/web/20080616065842/http://wirelessnomad.com/about and Wong, 2008). It did not succeed.

${ }^{9}$ For instance, FON describes itself as "the world's largest WiFi community" (http://www.fon.com/en/info/whatsFon). 
content and services, and facilitating communication with governments and among citizens) are summarized in Table 1. The table illustrates the potential complexities of getting connectivity in multiple locations, and indicates that relationships with multiple providers and use of various access technologies may be required. Individuals do have many choices as to how and where they will consume broadband services, but simply listing the various sources of broadband does not provide insight into whether these sources meet users' needs.

Table 1: Broadband Infrastructure Types and Providers

\begin{tabular}{|c|c|c|c|}
\hline & \multicolumn{2}{|c|}{ Service Type } \\
\hline & & Fixed & Mobile \\
\hline \multirow{3}{*}{ 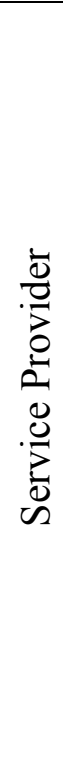 } & $\begin{array}{l}\text { Commercial } \\
\text { (For-Profit) }\end{array}$ & $\begin{array}{ll}\text { - } & \text { DSL } \\
\text { - } & \text { Cable } \\
\text { - } & \text { Fibre-to-the-home }\end{array}$ & $\begin{array}{ll}\text { - } & \text { Internet cafés } \\
\text { - } & \text { Fee for service wireless } \\
\text { hotspots } \\
\text { - Subscription-based } \\
\text { 3G/4G/WiMax services }\end{array}$ \\
\hline & $\begin{array}{l}\text { Public Sector/ } \\
\text { Government }\end{array}$ & $\begin{array}{ll} & \text { Municipal wireless projects } \\
\text { - } & \text { Municiping residences } \\
\text { - } & \text { projects } \\
& \text { Communility FTTH } \\
\end{array}$ & $\begin{array}{l}\text { Municipal wireless projects } \\
\text { serving public places }\end{array}$ \\
\hline & User/Citizen & $\begin{array}{ll} & \text { Individuals' open wireless } \\
\text { networks } \\
\text { - } & \text { Community wireless projects } \\
\text { - } & \text { Serving residences } \\
\text { User-owned FTTH networks }\end{array}$ & $\begin{array}{ll}\text { - } & \text { Community wireless projects } \\
\text { serving public places } \\
\text { - } \\
\text { Federated wireless sharing } \\
\text { (e.g. FON) } \\
\text { - } \\
\begin{array}{l}\text { Sharing of } 3 \mathrm{G} / 4 \mathrm{G} / \mathrm{WiMax} \\
\text { services }\end{array}\end{array}$ \\
\hline
\end{tabular}

\subsection{Assessing Broadband Infrastructures}

In an ideal world, there would be ubiquitous broadband access, offering seamless connectivity within cities (and beyond), and it would be easy to move from one city or country to another and maintain broadband access without needing to change providers or renegotiate access conditions. With ubiquitous availability, connectivity is available to its users wherever they want it.

Usability considers the extent to which the network is convenient and easy to use. For instance, does it provide service to a desirable, comfortable location? Can the service be used at any time of day or night? Is it easy to find the network? Is the connection process obvious and 
simple? Does the location of the connection allow the potential user a wide choice of access devices? Are there any restrictions on the use of the network?

Reliability and quality can be considered together. Is the network always available (and will it be available in the future from the same provider, i.e. is it sustainable)? Is the speed predictable and constant? Is the speed adequate for the desired use of the network? Is the quality sufficient to carry out desired activities (e.g. making telephone calls, streaming video, uploading or downloading photos)?

Security is another important issue for broadband providers. Users want assurances that their data transmissions are secure, so that their personal information cannot be intercepted or accessed by unauthorized people. Security is particularly important with shared broadband networks, as potential users must trust that the infrastructure provider is able to offer a secure networking environment that will protect personal data.

Good broadband infrastructure should also be affordable. While affordability is measured by individuals based on their overall incomes, are users likely to be able to manage the cost of connecting to a network as part of their household expenditures?

Given these criteria, ${ }^{10}$ how do the broadband infrastructures available in digital cities measure up? Beginning with fixed broadband services, it is noted that they do not provide ubiquitous coverage. Fixed line services from commercial providers and municipal or customerowned FTTH projects are expected to be secure, of high quality and to offer excellent reliability, as well as predictable long-term availability. Municipal and community wireless services may be less reliable or of lower quality, due to limitations of wireless technologies. These services are not always designed to provide fixed broadband access and there is no long-term guarantee of availability of service from these providers. ${ }^{11}$ There are also no guarantees of security, reliability, ongoing availability or service quality when 'piggybacking' on another user's broadband connection via $\mathrm{Wi}-\mathrm{Fi}$, but given the choice of service providers, it is easy to get a reliable, high quality fixed broadband connection in digital cities.

${ }^{10}$ These criteria are drawn from the Community Wireless Infrastructure Research Project's 'desiderata' for good broadband infrastructure (Middleton, et al., 2006; Bryne Potter and Clement, 2007). The desiderata offers a more detailed list of requirements for good broadband infrastructure, but a full consideration of the desiderata is beyond the scope of this paper. The criteria listed here are considered to be the most important in ensuring a good level of basic broadband connectivity within cities.

${ }^{11}$ As an example, the municipal broadband service in the City of Manassas, VA, was recently shut down after the council decided it was too expensive to maintain (Buske, 2010). 
Usability of fixed broadband infrastructure is high, as it provides service to indoor locations where there are comfortable working spaces. Affordability is dependent on users' income. However, commercial service providers offer a range of price points for their fixed broadband services, community and municipal providers do their best to provide low cost service, and piggybacking on other users' accounts is free. That said, there are other costs involved in getting access beyond the cost of broadband connectivity, and these do create real barriers to access (Dailey, et al., 2010). Fixed broadband is affordable for some, but not for everyone.

On the mobile side, there are differences between commercial $3 \mathrm{G} / 4 \mathrm{G}$ services and connectivity provided by the public sector, communities or individuals using Wi-Fi. The broadband connectivity delivered over commercial $3 \mathrm{G}$ and $4 \mathrm{G}$ mobile networks is best described as 'near ubiquitous'. Because users can 'take' their connectivity with them the service is highly usable, and provides access wherever they travel within cities. These connections are generally reliable, but may not offer the quality of service needed to support some applications (e.g. VoIP, which may be blocked by providers). The connection speeds are usually lower than those available with wired broadband services and more expensive (Broadband Choices, 2010), although ongoing investment in mobile infrastructure by telcos around the world is expected to improve mobile offerings in the next few years. International roaming plans let users provide their own connectivity in cities all over the world. Despite recent EU actions to make data roaming more affordable (European Commission, 2010), the costs can still be very high (Otsuka, 2009). Commercial mobile broadband services are reasonably good, offering convenience and flexibility for users, but at a cost that is not affordable for all. Mobile broadband services are a substitute for fixed line services, but for many mobile broadband subscribers their service is a supplement to fixed line connectivity. Paying for two services increases the overall cost of connectivity.

Services provided by the public sector, communities and individuals using Wi-Fi are often offered on 'best effort' basis. These services are not ubiquitous, serving specific local areas only. The providers do their best to ensure service availability, but there are no guarantees that a service will be available on an ongoing basis, especially if it is provided by an individual at a single location. Some municipal and community networks serve indoor locations (community centres, cafés), but others deliver primarily to outdoor locations, which limits their usability (Bryne Potter, et al., 2008). On the positive side, access to non-commercial Wi-Fi is generally 
affordable, and often free.

In cities, there are many options for getting access to broadband networks. The discussion above suggests that access in fixed locations is better than access while moving around cities. Although commercial mobile broadband does provide near ubiquitous service, it is expensive, so many users look for alternatives. As many efforts to develop municipal wireless projects have been unsuccessful, the wide-scale deployment of 'user-generated infrastructure' has been suggested as a way to offer connectivity to people as they move around cities. The promise of user-generated infrastructure is discussed below, followed by a discussion of a user-generated project that does not appear to be working well.

\section{The Promise of User-Generated Broadband Infrastructure}

It was thought to be "only a matter of time before ubiquitous voice and broadband access services based on public Wi-Fi emerge[d] in town and city centres across Europe" (Francis, et al., 2006, p. 1), and presumably elsewhere. Yet several years later, the promise of widely available public Wi-Fi has not been realized. Although there are some notable exceptions ${ }^{12}$ public Wi-Fi has not been deployed on the scale that was predicted.

When Internet users are unhappy with available services, they develop their own alternatives. User-generated content (Hardey, 2007; OECD Directorate for Science Technology and Industry, 2007) is the most prevalent example. But users are also creating alternative Internet access infrastructures, taking advantage of the ease of deploying Wi-Fi networks to make the Internet available on their own terms. One such example of user-generated infrastructure is FON, a Wi-Fi sharing project that originated in Spain (Becker, et al., 2008). FON has garnered much interest as a means of extending Internet access within cities.

Francis et al. (2006) make a case for "Open Broadband Access Networks." Noting that average households use less than $2 \%$ of the capacity of their wired broadband connections, they suggest that making surplus bandwidth available to the public through wireless access points can provide greater returns on investment in wired broadband infrastructure. In addition, this

\footnotetext{
${ }^{12}$ See for instance the Wireless Leiden project covering the Leiden and surrounding communities in the Netherlands (http://www.wirelessleiden.nl/en/about-wireless-leiden), Saskatchewan! Connected in Canada (http://www.ito.gov.sk.ca/wireless-internet) and the SparkNet-OpenSpark project in Turku, Finland (Tallberg, 2006), https://open.sparknet.fi/index.php. Danigelis (2008) provides a list of cities with extensive Wi-Fi availability.
} 
approach would create a wireless network to supplement (or perhaps compete with) existing cellular network infrastructure. This approach would likely be driven by existing Internet access and service providers, but others see opportunities for more community-centric approaches.

Markendahl and Mäkitalo (2007b) also note the potential efficiencies to be gained by sharing existing infrastructure. They discuss 'co-operating private networks,' where various individuals or small private networks collaborate by using some sort of coordinating agency to allow mutual access to each other's networks. It is suggested that the main driver for this approach is "the idea of cheap or free [wireless Internet] access [for] everybody without a traditional operator" (p. 4). Damsgaard and colleagues (2006) call this approach a 'wireless commons', explaining how it is possible for individuals to cooperate to optimize outcomes for all participants. While it is difficult to remove network operators from the picture entirely (after all, they are providing the bandwidth that is being shared), Ohira and colleagues (2007) believe that there is increased interest in offering access to the public over individuals' own personal networks. Arguing that outdoor Wi-Fi coverage is needed, Thompson and colleagues (2007) suggest that it can be provided at low cost, and on a global scale, through sharing of private broadband networks.

Sharing is motivated either by the hope of making money, or in the spirit of cooperation (Ohira, et al., 2007). Individuals who participate in peer-to-peer hotspot sharing can "gain substantially by getting access to other individuals' WLAN access points and [are] able to get connected to broadband Internet services widely" (Tallberg, 2006, p. 5). While sharing is an appealing concept, Wong and Clement (2007) report that most individuals they surveyed were more interested in getting access to others' networks than in sharing their own connections. Damsgaard et al. (2006) outline ways that users' online behaviors can reduce the quality of the shared networks (using a tragedy of the commons argument), but note that if many people are willing to share their network connectivity, "there is potential for a comprehensive and robust infrastructure" (p. 106). For those who do share, Markendahl and Mäkitalo (2007b) emphasize that such initiatives can benefit users by providing them with the bandwidth of fixed broadband networks combined with the availability of cellular networks.

The literature suggests that sharing is both useful and possible, and that the power of communities could be used to build broadband infrastructures that parallel existing networks and offer alternative approaches to infrastructure provision. FON is one of the better known projects already working to develop shared broadband infrastructure, but it is not the only one (Farkas, 
2008). Open source software programs like 'NoCatAuth' ${ }^{13}$ and 'wifidog' ${ }^{14}$ are available to manage user authentication for multiple wireless hotspots. Other groups (e.g. CuWIN, freifunk, Open-Mesh ${ }^{15}$ ) have focused on developing open source software that enables meshing (e.g. CUWiNware, DD-WRT and OpenWRT ${ }^{16}$ ). Whisher ${ }^{17}$ offers software for sharing Wi-Fi on a reciprocal basis.

\section{FON Case Study}

FON was founded by Argentinean entrepreneur Martin Varsavsky, in an effort to build a mobile Internet. Disappointed by the slow rollout of $3 \mathrm{G}$ mobile broadband infrastructure, Varsavsky describes FON as a fight for a better Internet, deployed by Wi-Fi, on a person by person basis (Simon, 2005). Varsavsky's "WiFi revolution" was officially launched in Madrid, Spain, in February 2006, but was first announced in November $2005 .{ }^{18}$ Within 10 days of the unofficial launch, FON hotspots were operational in 18 countries.

The FON 'movement,' as Varsavsky christened it, allows individuals who are willing to share their personal broadband connections (known as 'Foneros') free use of the broadband connections of other Foneros around the world. As the movement grows, Varsavsky envisions a world where FON enables ubiquitous and universal Wi-Fi. His concept is simple. FON acts as an aggregator, offering a brand and identity for Wi-Fi hotspots provided by individuals. As more individuals join FON, more connectivity is available for all Foneros.

Between 2006 and 2008 FON received approximately \$44 million (USD) from venture capital and private sector investors. ${ }^{19}$ It burned cash at a rapid rate in its early years (Varsavsky, 2008), but by September 2009 the company was breaking even (with revenues from the sale of hardware that allows people to set up FON hotspots, and from fees paid by non-Foneros to access FON hotspots). Varsavsky states that the outlook for 2010 is promising (Varsavsky,

\footnotetext{
${ }^{13} \mathrm{http}: / /$ nocat.net

${ }^{14}$ http://dev.wifidog.org/wiki/FAQ

${ }^{15} \mathrm{http}: / / w w w . o p e n-m e s h . c o m$, http://wiki.freifunk.net/Kategorie:English, http://www.cuwin.net/about

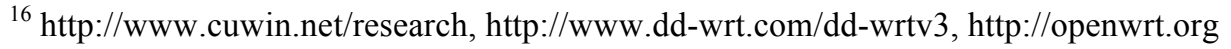

${ }^{17} \mathrm{http}: / /$ www.whisher.com/about_us.php

${ }^{18} \mathrm{http}$ ///blog.fon.com/en/archive/general/fon-has-gone-live.html

${ }^{19} \mathrm{http}: / /$ venturebeatprofiles.com/company/profile/fon
} 
2010), but the company does not release financial results.

To create a hotspot, a person connects a FON router to a broadband connection. A FON hotspot broadcasts two secure signals ${ }^{20}$ - a private signal, for use by the hotspot owner (the Fonero), and a public signal for sharing the Internet connection. The Fonero can decide how much bandwidth to allocate to this public signal. Foneros can access other FON hotspots free of charge. Anyone else can access a hotspot on a pay-per-use basis (pricing varies by country), and the hotspot owner can choose to receive a percentage of this revenue. ${ }^{21}$ FON provides a central database of hotspots on its website. ${ }^{22}$ Potential users can enter an address anywhere in the world and find out whether there are any FON hotspots nearby. Once a FON hotspot is located on the map, the user goes to the hotspot with a Wi-Fi device, logs in (or signs up for the service), and then has access to the Internet. FON states that it is "the world's largest WiFi community", with two million members and 1.5 million hotspots around the world. ${ }^{23}$

Varsavsky argues that FON can drive broadband uptake, encouraging people to get broadband at home so that they will have roaming access to broadband around the world. $\mathrm{He}$ observes that because users must have a broadband subscription they are willing to share in order to get free access to FON, FON is good for ISPs as well as individuals (Reinhardt, 2006). FON helps Internet providers to facilitate roaming for their clients, without having formal roaming agreements with other ISPs. FON has negotiated alliances with Internet service providers in Russia, France, Japan, the US and the UK (Associated Press, 2007; Markoff, 2008; BT and Fon, 2010). Revenues generated by use of FON hotspots are shared with ISPs when the ISP has an agreement with FON.

It may seem odd that a private company is described as offering user-generated infrastructure, but the business model is dependent on community members making their hotspots available to the 'movement.' FON facilities the creation of user-generated infrastructure. There is no FON network, but by building an infrastructure that provides information on the location of hotspots and supports billing (allowing FON and Foneros to make money) it gives

\footnotetext{
${ }^{20} \mathrm{http} / / / \mathrm{www} \cdot$ fon.com/en/info/security

${ }^{21}$ See http://english.martinvarsavsky.net/fon/fon\%C2\%B4s-new-pricing-structure-and-products.html for the current pricing structure.

${ }^{22} \mathrm{http} / / /$ maps.fon.com/?lang=en

${ }^{23} \mathrm{http} / / /$ blog.fon.com/en/archive/foneros/fon-hits-2-million-member-mark.html
} 
individuals a structured way to make their broadband connections available to others. The premise is win-win - FON provides Wi-Fi sharing on a global scale, and Foneros get free access when they are away from home. FON has been enthusiastically embraced and promoted worldwide, with many individuals investing significant time and effort to advance FON (e.g. by participating in FON's forums ${ }^{24}$ and/or creating blogs promoting the use of $\mathrm{FON}^{25}$ ).

FON's approach appears to offer an organized way to unite many individual, distributed broadband 'providers' to collectively provide a single service. "The dream of having free and ubiquitous Wi-Fi everywhere is extremely alluring and it is clear and understandable that FON has a large community of eager believers," says blogger Veldhuijzen van Zanten (2008). As he says, "FON makes for a great story." But is FON just a great story, or does it actually deliver usable infrastructure that provides connectivity to citizens in digital cities? This question is addressed below.

\section{Assessing FON's Contribution to Broadband Infrastructure in Cities}

To the best of our knowledge, few studies have assessed the FON approach to providing broadband infrastructure by studying FON users and/or assessing the usability of FON hotspots. Becker and colleagues (2008) surveyed 268 early adopters of FON in Germany, noting technical and legal barriers to the development of the FON community. Su et al. (2008) also surveyed FON users, seeking to understand how willing they were to share their bandwidth. The details of this study are not clear, but the authors conclude that a positive attitude towards FON influences intention to use FON. Hariri (2007) tested FON hotspots in Vienna, finding that Internet access was only possible in 4 of 11 hotspots noted on the FON maps, and that 2 of these 4 hotspots provided very slow connections.

FON's great promise is that there are many FON hotspots, and a potential user simply checks the map, locates a hotspot and goes and connects to it. But just $50 \%$ of Foneros surveyed by Becker et al. (2008) made their hotspots available 24 hours a day, 7 days a week (24/7). Our own efforts to connect to FON hotspots in various cities in Austria, Canada and the UK revealed that many hotspots on the map could not be detected from the street, while those that could be

\footnotetext{
${ }^{24}$ http://boards.fon.com

${ }^{25}$ Blogs in English include myfonblog.blogspot.com, blog.fonosfera.org, www.fontastic.org (last updated in mid2008) and Spreadfon (archived at http://web.archive.org/web/20080210192246/http://spreadfon.org).
} 
detected were not accessible (i.e. the signal could be detected, but an Internet connection could not be established), or offered very slow Internet access. Visiting hotspots just once does not provide a true indication of their availability over time, but the whole value proposition for providing public broadband access is that connectivity is available to users when they need it. Users may only need mobile broadband access in a particular location once. As such, a FON hotspot that is not functional when a potential user visits is of no value to that user, even if it is functional at other times.

This section considers the question of whether the FON community provides good mobile broadband, broadband that meets the needs of citizens moving about digital cities. As discussed earlier, good broadband should be ubiquitous, usable, of high quality, reliable, sustainable, secure and affordable. Given the challenges in actually locating functional FON hotspots, our assessment draws on a wide variety of sources, going beyond tests of FON hotspots to include published descriptions of FON, interviews with community wireless experts and FON users, postings to FON web forums, and independent blogs. ${ }^{26}$

\subsection{Ubiquity}

Proponents of community-led wireless initiatives suggest that it is possible to create infrastructure that parallels the existing cellular telephony network. In order to do this, network ubiquity is essential. While ubiquity may have geographic bounds (e.g. coverage within a suburb or city as opposed to coverage of a region), the question here is whether the network is available to its users wherever they would like to use it.

In promoting FON as a means of providing broadband connectivity to individuals as they travel around the world, there is an expectation that coverage is available where those individuals travel. But despite FON's alliance with BT in the UK, and with other ISPs around the world, FON's network coverage is far from ubiquitous. Indeed, people looking to use the FON 'network' often have extreme difficulties in locating a single FON hotspot that is usable (let alone in a convenient place). FON's offering to date is certainly not a feasible alternative to existing infrastructure provided by Internet service providers and mobile operators, and the business model is not likely to enable the worldwide connectivity Varsavsky envisioned for his 'Wi-Fi

\footnotetext{
${ }^{26}$ The FON community is multilingual, but the data presented here are based primarily on analysis of the experiences of English language 'Foneros.'
} 
revolution.'

FON says that it has two million members and 1.5 million hotspots around the world, but many observers suggest that these numbers are inflated. In 2006, Mike Puchol outlined detailed calculations estimating that of the 20,000 routers shipped by FON to that date, fewer than 3,700 were actually online (Puchol, 2006). In an interview, El Fon blogger Chad Vanderlinden explains that "the FON maps will show all the hotspots that have been registered in an area, whether they've been up for the last hours or not. The map could include [hotspots with] months of not having been up. It could be that [the hotspot provider] got it registered, didn't like the idea, shut it off right away. Six, eight months, a year later, the icon could still be there." Veldhuijzen van Zanten (2008) concurs, noting that:

If you have set-up a FON hotspot in the past you must enter a request to have it removed from their maps. If you don't they still count you in their media and investor statistics, as a live FON Hotspot. Of the FON Hotspots that are actually live only a small percentage will be an actual hotspot when people accidentally stumble upon it.

The FON maps now have the option of displaying only hotspots that have been active in the past hour, but there are still disputes over the numbers of hotspots that are actually registered and available for use. In contrast to the 1.5 million hotspots Varsavsky claims are operational, FrancoFON (representing French FON community members) counts about 675,000 active FON hotspots in the northern hemisphere as of April 2010. ${ }^{27}$ Varsavsky noted 950,000 hotspots in the UK, but FrancoFON's data suggests there are just over 500,000 in the UK. ${ }^{28}$

Despite the disparity in these numbers, there should be many active FON hotspots. FON does not provide ubiquitous coverage, but where the FON maps show an active hotspot, people should be able to connect to it. Ideally, users would share the experience of the individual who recently noted on a BTCare Community Form that he has "been using BT Fon in the UK and it works very well". But for other users, this is not the case:

${ }^{27} \mathrm{http}$ //www.francofon.fr/myiframe-index.iframeid-4-export-gps-poi-fon-maps-francofon-fr.htm, visited April 10, 2010.

${ }^{28}$ Most of the FON hotspots in the UK are provided through the partnership between commercial fixed broadband provider BT and FON. As of March 2009, new BT customers are automatically enrolled in BT Fon (https://www.bt.com/wifi/secure/whatsBTFon.do), increasing the number of BT FON hotspots that are theoretically part of the FON community. However, it is not clear that new customers understand what BT FON is about, or that they take any steps to ensure that their FON hotspots are active and available. Further research on the BT FON partnership is warranted. 
I have just returned from holiday having hoped to have been able to use my new status as a member of BT FON to check my e-mails. Before I went I printed out a precise location map of the local town and during the week I spent about an hour visiting almost every one of the marked hotspots but I never succeeded in locating any of them! (comment on BTCare Community Forums, August 2008)

In the three years that I have been with FON, I never found a working FON hotspot when I needed/wanted one. It is a lot easier to find an open hotspot than to find a working FON spot. (comment on FON Boards, July 2009)

As a BT Broadband Anywhere user, I never found a single FON hotspot apart from my own in 18 months, and like a lot of us from that forum, it certainly wasn't for want of trying. (comment on BTCare Community Forums, February 2010)

I tried in France and Spain last November without any luck. It's very difficult finding a site from the map provided on the internet. (comment on BTCare Community Forums, March 2010)

People who are unhappy with the service are more likely to post comments to forums than those who are happy. But data from Foneros themselves (Becker, et al., 2008) also revealed that very few individuals are actually using their hotspots. This leads to questions about the usability of the FON community infrastructure.

\subsection{Usability}

If the FON service is to provide value to its users, it must offer convenience and be easy to use. When Foneros share their home broadband connections, by definition their FON hotspots will be in their homes, which are located in residential areas. As noted in a comment to the GigaOm blog, ${ }^{29}$

The biggest problem with FON is that they are targeting residential Internet users and therefore the hotspots will be in residential areas. The stereotypical road warrior who wants to find a hotspot is going to be in the business or industrial parts of town.

The hotspots could be used by people living nearby, but in order to get free access, they would also have to have their own hotspot, in which case they wouldn't need to share with their neighbors. Observing that no one he didn't already know had ever used his FON hotspot, Vanderlinden offers this explanation: "I guess we don't have any neighbors who don't have high speed Internet or Wi-Fi already."

${ }^{29} \mathrm{http} / /$ gigaom.com/2007/04/23/fon-time-warner-deal-confirmed 
Additionally, when users do find a working FON hotspot, they do not typically knock on the hotspot owner's door and ask to come in and use the Wi-Fi connection. Instead, they access the device from outside, perhaps from a corridor in an apartment building, but more likely while standing on the street. Outdoor access may be sufficient for quickly checking something on a smart phone, but is likely to be inconvenient for anyone seeking connectivity to browse the Internet, access a government service, or read or respond to email.

\subsection{Reliability and Quality}

Given that FON uses existing broadband connections as the basis for shared Internet access, such access is only as reliable as the primary connection on which it is based. This means the quality can vary from hotspot to hotspot. At various times, FON has given away large numbers of routers, with the objective of expanding its network. The Fonera 2.0 router may attract new customers because of its features, not because they are particularly interested in sharing their WiFi signal. Consequently, some people may set up a FON router for their own use, without much attention being paid to the fact that in setting up their router they have also agreed to create, and created, a public hotspot.

Because the routers used by FON are designed for providing service inside buildings, their signal strength is not always particularly strong outdoors (Yao and Chen, 2007) so connectivity at accessible FON hotspots is often of low quality. FON members may not position their routers in order to optimize signal strength outdoors, and there are no service guarantees (Markendahl and Mäkitalo, 2007a). Although the agreement with $\mathrm{FON}^{30}$ requires members to keep their routers active on a 24/7 basis, the FON maps show that many hotspots are not active.

Reliable infrastructure needs to be available on a consistent basis, but with the FON model providers have few reasons to check the reliability of their hotspot's performance. As noted, there are many reports of hotspots that are either completely inactive, or visible but not usable. It is likely that most Foneros set up their routers in good faith, embracing FON's philosophy of sharing, but in reality, this does not stop an average Fonero from disconnecting, or degrading the quality of their hotspot (perhaps inadvertently). Relying on the goodwill of Foneros alone as a means of quality control does not result in the provision of good public broadband infrastructure.

\footnotetext{
${ }^{30} \mathrm{http}: / /$ static.fon.com/images/media/en/en_general_conditions.pdf
} 


\subsection{Sustainability}

Despite FON founder Varsavsky's optimism that 2010 is "the year of FON" (Varsavsky, 2010), there are no guarantees that the company will exist in the long term. As Vanderlinden argues (El Fon Blog, 2008), the only way that FON provides value to the FON community is by maintaining the database of FON hotspots, and by providing the authentication and billing system. It appears that the database is not particularly accurate, and few people draw much benefit from the existence of the network (devaluing the billing and authentication infrastructure).

FON is highly reliant upon the goodwill of its community members to keep the infrastructure in place, and this goodwill is dissipating. ${ }^{31}$ Individuals are frustrated that FON does not listen to their suggestions for improving the FON user experience, and feel that the company is no longer about community, but is simply another business venture for its founder. There is little loyalty to FON, and limited economic incentives for Foneros to remain committed to the project (Markendahl and Mäkitalo, 2007a). As such, the long-term prospects for the FON network seem uncertain at best, suggesting this is not an approach to build sustainable infrastructure.

\subsection{Security}

Security is an important concern for people sharing wireless network connections. Members of the FON community have asked questions about its security since its inception, and according to FON websites, "FON is safe." ${ }^{32}$ Martin Varsavsky writes in his blog that worrying about security "is really unnecessary," ${ }^{33}$ an approach that some security experts agree with (e.g. Schneier, 2008). But Varsavsky's platitudes do not satisfy many in the FON community. FON networks are not encrypted, and there is evidence to suggest that not all aspects of the network are secure (Björck, 2007). Members of the FON community have suggested to FON that support for virtual private networks (VPNs) could be added to the Fonera to improve security for hotspot users. ${ }^{34}$ The fact that people continue to participate in the FON community suggests that there is a comfort level with FON's approach to security, but there is room for improved security

\footnotetext{
${ }^{31}$ See the Community Resistance section of the El Fon Blog, for example: http://elfonblog.fondoo.net/?cat=44.

${ }^{32} \mathrm{http}: / /$ www.fon.com/en/info/security

${ }^{33} \mathrm{http}: / /$ english.martinvarsavsky.net/fon/fon-security.html

${ }^{34}$ FON users have shared their workarounds for enabling VPN access on the FON wiki. It is enabled for Foneras sold in the UK.
} 
measures.

\subsection{Affordability}

FON aims to provide Wi-Fi everywhere, but there is no evidence that there is a focus on ensuring that 'Wi-Fi everywhere' is affordable to users. As has been explained, in order to get 'free' roaming broadband through FON, a Fonero must already have a broadband connection with an active FON router attached to it, operating a FON hotspot. So FON members are paying their own Internet service provider for Internet access, in addition to any costs they incurred in obtaining a FON router. That said, they should be able to avoid additional costs for roaming Internet access, if they can make use of FON hotspots while away from home.

For non-Foneros who connect to FON hotspots (if they can find them), FON provides free access to Gmail, Google maps, news and search. ${ }^{35}$ Arguably, given these free offerings, FON does provide affordable connectivity to users to carry out basic online activities. But using FON as a regular paid user does not make much sense, as there are cheaper, more reliable options. People needing to connect for more than a few days would likely be better served with a mobile broadband connection from a cellular telephony provider, or by a contract with a commercial hotspot operator.

Some people may find that FON hotspots meet their needs for intermittent mobile broadband connectivity, but as it is currently designed, the FON approach does not provide ubiquitous, usable, high quality, reliable, and affordable mobile broadband infrastructure. As indicated in Table 1, FON is just one method for users to generate mobile broadband infrastructure, but it does not appear to produce sufficiently robust infrastructure to make a positive contribution to connectivity in digital cities. The implications of this assessment are discussed below.

\section{Discussion}

Despite its shortcomings, the FON model helps to illustrate the challenges of building reliable broadband infrastructures by aggregating individual access points. Some of the shortcomings in the FON approach relate to FON itself, but others are more general problems that could be faced by any group of users attempting to develop their own infrastructure.

FON is an interesting case because it is a for-profit company attempting to develop

\footnotetext{
${ }^{35}$ http://blog.fon.com/en/archive/general/gmail-and-fon.html
} 
infrastructure based on contributions by community members. It is building (aggregating) usergenerated infrastructure, but there is a tension between FON's corporate objectives and community members' objectives. As one commenter said in response to a blog posting lamenting the commercialization of FON and the demise of 'the Wi-Fi Revolution', "The thing is that many people around the world were inspired by the very idea of FON revolution. And now there is no revolution. ${ }^{136}$ So if community members who are disillusioned by the corporate focus choose not to keep their routers active, or to withdraw from the community, it is difficult for FON to bring them back. Indeed, the growth of the FON community in recent years has been driven by FON's partnerships with ISPs, and it appears that there is less buy-in on the part of the ISPs' customers to the whole FON concept. ${ }^{37}$ Building a network of hotspots based on the infrastructure of those who are indifferent to sharing creates problems in terms of being able to ensure hotspot availability and deliver high quality connectivity. Indifferent or disillusioned community members also hinder the creation of positive "network effects" which are important in achieving a critical mass of hotspots (Becker, et al., 2008).

Thus, some of the barriers to the development of ubiquitous, reliable and high quality infrastructure described here are related to FON itself, but would likely exist for any other commercial entity trying to develop a business relying on the goodwill of a disparate group of individuals. As a commercial entity FON has contributed a working infrastructure for branding and billing, raised awareness of FON and expanded its capacity through partnerships with ISPs, and managed the distribution and mapping of FON routers. These contributions are not trivial. Despite problems in the overall availability and usability of many hotspots, FON has added to the broadband connectivity options available for mobile users.

The challenge of scale, and creating positive network effects to create ubiquitous, usergenerated infrastructures are not unique to FON, nor are issues regarding affordability and usability of the infrastructure. Issues of scale are considered below, followed by a discussion of ways to improve broadband infrastructures available to people moving around digital cities.

Sawhney's Infrastructure Development Model $(1992 ; 2003)$ suggests that to become firmly

\footnotetext{
${ }^{36}$ See http://www.milanin.com/members/andrey.golub/weblog/529.html.

${ }^{37}$ The BT FON FAQ page includes a section titled "I have been told I am a member of BT FON - what does this mean?" (http://www.btfon.com/support/faqs) suggesting that many customers do not understand what the FON community is about.
} 
established and provide services on a large scale, a new infrastructure must compete with, and then supersede, an old one. In his 2003 consideration of the bottom up development of wireless networks, Sawhney noted that such networks were initially established as independent 'islands' of connectivity. He anticipated that individual networks could be united to provide coverage across larger geographic areas (as has happened to a certain extent with FON), but argued that it was unlikely that wireless infrastructures could be joined together on a sufficiently large scale to provide coverage that would compete with wired infrastructures.

Real competition would require decoupling the wireless network from the fixed line network, and this would require a shift in operating assumptions. Extending an existing network from the bottom up (FON's approach) is very different from operating a standalone network. For instance, users would need to make arrangements to provision network 'backhaul' to connect their Wi-Fi hotspots to the Internet (rather than using another provider's fixed broadband link). This would effectively result in users becoming their own infrastructure providers, which is quite different than sharing existing infrastructure. However, this independence from existing providers could result in improved broadband availability for users, as the competing service would provide a real alternative to existing fixed (and mobile) options.

As illustrated in Table 1, sharing existing infrastructure is just one of many ways to provision mobile broadband. This paper has explored some reasons why this approach hasn't been entirely successful for FON. To recap, it is difficult to establish infrastructure on a scale that makes it widely available, especially when relying on the goodwill of individuals to make their own access points available. As an organizing or coordinating agency, FON has no power to enforce its user agreement (to ensure 24/7 hotspot availability), and its strategy of extending the network through partnerships with ISPs means that many hotspots have been added without their owners fully understanding, or committed to, the nature of the project. As such, FON may be viewed by some community members as a novelty, rather than as a serious effort to provide others with, and have access to, usable broadband connectivity away from their homes.

In terms of usability, user-generated infrastructure that is built out from citizens' fixed broadband networks will always have difficulty providing connectivity everywhere that people moving about a city want it. Affordability will also be an issue for any community developing a shared broadband infrastructure. There are real costs to sharing, in terms of coordination (determining parameters for the shared infrastructure, identifying community members, 
establishing communication protocols and usage norms), development of appropriate hardware and/or software solutions to enable the technical aspects of sharing, and establishing capacity within the community to allow people to contribute their infrastructure to the collective project. These costs can be shared among community members, and may also be recouped from noncommunity members who make use of the infrastructure.

This case study suggests that the problems with user-generated infrastructure are both technical and social, and neither are easily resolved. The social issues relate to human nature, in terms of incentives to share and to act in an altruistic manner in the hopes of being the beneficiary of someone else's altruism. These influence the technical provision of connectivity, because hotspot availability is dependent on individual behaviours, rather than on the actions of a single technology provider. As a result, it is unlikely that user-generated infrastructure will ever deliver ubiquitously available, secure, high reliability, high quality, and highly usable broadband connectivity. However, user-generated infrastructure may offer more affordable options for people moving around cities than commercial broadband services, and may be a useful 'stop gap' solution for those who cannot afford a commercial service, or require connectivity only intermittently.

Tapia and colleagues (2009, p. 354) call for the development of 'hybrid public broadband,' infrastructure "that is neither completely bottom up nor top down" and delivers the best aspects of municipal and community broadband infrastructures to meet the needs of the public. A hybrid approach could expand the scope of the users involved in providing infrastructure. By encouraging other entities (e.g. municipal/public sector agencies) to share their connectivity in 'desirable' locations not reached by citizen's fixed broadband services, availability and usability could be improved.

Although there were problems with municipal wireless infrastructure projects in their first iteration, there may be good opportunities for municipalities to re-establish a role in providing mobile broadband infrastructures when they develop fibre networks. Whether providing fibre-tothe-home services (perhaps through a utility company), or developing a fibre network to serve the needs of municipal governments, the fact that municipalities are investing in fibre makes it easier for them to overlay wireless connectivity to support affordable mobile access by citizens. ${ }^{38}$

\footnotetext{
${ }^{38}$ This was key to the success of the Fred-eZone in Fredericton, NB, Canada (Powell, 2008a).
} 
Another opportunity for user-generated infrastructure, with or without municipal involvement, may come with the 'digital dividend.' The move to digital television frees up valuable spectrum that can be used to provide wireless broadband connectivity, with much better range and at higher quality than existing Wi-Fi services (Meinrath and Calabrese, 2008), making it more feasible and affordable for users to develop reliable broadband infrastructure to support mobile connectivity.

\section{Conclusion}

This paper makes several contributions to an understanding of broadband infrastructure provision in digital cities. Given the importance of broadband connectivity to support citizen access to government services, to educational and entertainment content, and to engage with each other, it is essential to recognize characteristics of good broadband infrastructure, and to consider what steps can be taken to improve its availability. The comparison of fixed and mobile broadband revealed that despite its lack of ubiquity and concerns about affordability, urban citizens have reasonable options for accessing good fixed broadband services. Mobile broadband offerings are better than fixed offerings at providing connectivity for people on the move, but often this mobility comes at a higher price for lower quality service. The discussion of service providers illustrated the possibility of developing new mobile broadband services by aggregating individual Wi-Fi hotspots to serve a community of users.

Using the FON community as an example, the study identified difficulties for citizens wishing to develop their own broadband infrastructures. The findings are consistent with Sawhney's (1992; 2003) and Sandvig's observations on infrastructure development. Sandvig asks:

When is a decentralized, cooperatively run communication infrastructure a significant alternative to the centrally driven, commercial systems that have historically prevailed? The research literature on utility and communication infrastructures answers, "almost never," or "only in the early stages of a system."

(Sandvig, 2004, p. 580)

FON founder Martin Varsavsky proudly describes FON as being "like a telephone company built by the people" (Markoff, 2008). The problem is that FON is exactly like a telephone company built by individuals, without the benefit of the expertise, resources, and scale of a 
commercial operator, and with the challenge of convincing multiple individuals of the value of altruism in sharing connectivity for the benefit of FON and the FON community. This observation does not suggest that infrastructures must be built by the commercial sector, but rather that there is a need for scale and for central coordination that are not easily achieved by the ad-hoc nature of many community efforts.

What then are the prospects for the development of good public infrastructures to enable connectivity in digital cities? The discussion here suggests that although user-generated approaches can contribute useful islands of connectivity in the short term, they are unlikely to provide the usable, reliable infrastructure needed as a platform for a digitally engaged citizenry. There are already good options for fixed broadband provision, and opportunities for municipalities, as organizations with access to the resources and expertise needed to build infrastructures that serve the public interest, to play a larger role in the development of infrastructure that will enable the anytime, anywhere, user friendly, reliable connectivity that is becoming expected in digital cities. A hybrid approach to broadband development, bringing together users and the public sector to develop wireless or fiber networks that can be used as a platform for service delivery and infrastructure provision, is also worthy of further study when seeking to understand how to provision connectivity in the digital city of the future. 


\section{Acknowledgements}

\section{References}

Associated Press, 2007, 24 April. Time Warner broadband deal to allow users to share access. New York Times.

Australian Bureau of Statistics, 2010. Internet activity, Australia, December 2009 - Internet subscribers by access connection, for ISPs with more than 1,000 active subscribers. http://www.abs.gov.au/AUSSTATS/subscriber.nsf/log?openagent\&81530do001_200912. xls\&8153.0\&Data\%20Cubes\&6F717ADDA2F1D1F0CA2576F50011B2C7\&0\&Dec\%2 02009\&30.03.2010\&Latest. (accessed 30 March, 2010).

Becker, J. U., Clement, M., et al., 2008. Shared WiFi-communities - user generated infrastructure am beispiel von FON. Wirtschaftsinformatik 50, 482 - 488.

Björck, F., 2007. FON security scenarios. http://security.dj/. (accessed 10 March, 2009).

Broadband Choices, 2010. Mobile broadband vs fixed line broadband. http://www.broadbandchoices.co.uk/partner-lp mobile-broadband-voip-130209/mobilebroadband-vs-fixed-line-broadband.html. (accessed 8 April, 2010).

Bryne Potter, A., Clement, A., 2007. A desiderata for broadband networks in the public interest. Telecommunications Policy Research Conference, Arlington, VA.

Bryne Potter, A., Mcintyre, N., et al., 2008. How usable are outdoor wireless networks? Canadian Journal of Communication 33, 511-524.

BT, Fon, 2010. The Wi-Fi community built by you. (accessed 13 August, 2010).

Buske, J., 2010. Manassas to end broadband-over-power line Internet service. http://www.washingtonpost.com/wpdyn/content/article/2010/04/06/AR2010040603796.html. (accessed 8 April, 2010).

Center for Digital Government, 2008. Digital cities survey. e.Republic, Folsom, CA. http://media.govtech.net/Digital Communities/CDG 2008 Digital_Cities_Survey_Execu tive Summary.pdf. (accessed 26 April 2009).

Cho, H. H.-N., 2008. Towards place-peer community and civic bandwidth: A case study in community wireless networking. Journal of Community Informatics 4.

Dailey, D., Bryne, A., et al., 2010. Broadband adoption in low-income communities. Social Science Research Council, Brooklyn, NY. http://webarchive.ssrc.org/pdfs/Broadband_Adoption_v1.1.pdf.

Damsgaard, J., Parikh, M. A., et al., 2006. Wireless commons perils in the common good. Association for Computing Machinery. Communications of the ACM 49, 105-109. 
Danigelis, A., 2008. 10 cities with widespread wireless Internet. http://dsc.discovery.com/technology/tech-10/wireless-cities-top.html. (accessed 10 April, 2009).

Department for Culture Media and Sport, Department for Business Innovation and Skills, 2009. Digital Britain - Final report June 2009. Office of Public Sector Information, Kew, Richmond, Surrey. http://www.culture.gov.uk/images/publications/digitalbritainfinalreport-jun09.pdf. (accessed 16 June 2009).

El Fon Blog, 2008. FON does not split money 50/50. http://elfonblog.fondoo.net/?p=106. (accessed 24 April, 2009).

European Commission, 2010. Telecoms: Mobile phone customers entitled to protection from data-roaming "Bill shock" As from 1st March 2010. http://europa.eu/rapid/pressReleasesAction.do?reference=IP/10/215. (accessed 6 April, 2010).

Farkas, P. A., 2008. Alternative municipal wireless network models. Examination of grassroots and ad-based initiatives. Third International Conference on Communications and Networking in China, 2008.

Federal Communications Commission, 2010. Connecting America: The national broadband plan. FCC, Washington, DC. http://download.broadband.gov/plan/national-broadbandplan.pdf. (accessed 16 March 2010).

Fiber-to-the-Home Council, RVA LLC, 2009. 2009 consumer FTTH and broadband survey. http://www.ftthcouncil.org/sites/default/files/2009Consumersurveykeyfindings\%20FINA L.pdf. (accessed 19 September 2009).

Forlano, L., 2008. Anytime? Anywhere?: Reframing debates around community and municipal wireless networking. Journal of Community Informatics 4.

Francis, J. C., Elnegaard, N., et al., 2006. Business opportunities of open broadband wireless access networks. Proceedings of the 2006 workshop on broadband wireless access for ubiquitous networking, Alghero, Italy.

Hardey, M., 2007. The city in the age of web 2.0 - a new synergistic relationship between place and people. Information, Communication \& Society 10, 867 - 884.

Hariri, K., 2007. Road test: Availability of FON hotspots in vienna. http://kyros.at/fon/Road_test_availability_FON_hotspots_in_Vienna.pdf. (accessed 10 April, 2009).

Horrigan, J., 2009. Home broadband adoption. Pew Internet \& American Life Project, Washington, DC.

Hudson, H. E., 2010. Municipal wireless broadband: Lessons from San Francisco and Silicon Valley. Telematics and Informatics 27, 1-9. 
Industry Canada, 2009. Broadband Canada: Connecting rural Canadians - about the program. http://www.ic.gc.ca/eic/site/719.nsf/eng/h_00001.html. (accessed 28 July, 2009).

Ishida, T., 2002. Digital city Kyoto. Communications of the ACM 45, 76-81.

Johnston, N., Aghvami, H., 2007. Comparing WiMAX and HSPA -- a guide to the technology. BT Technology Journal 25, 191-199.

Kleinrock, L., 2001. Breaking loose. Communications of the ACM 44, 41-46.

Lehr, W., McKnight, L. W., 2003. Wireless Internet access: 3G vs. WiFi? Telecommunications Policy 27, 351-370.

Lemstra, W., Hayes, V., 2009. License-exempt: Wi-Fi complement to 3G. Telematics and Informatics 26, 227-239.

Markendahl, J., Mäkitalo, Ö., 2007a. Analysis of business models and market players for local wireless Internet access. 6th Conference on Telecommunication Techno-Economics.

Markendahl, J., Mäkitalo, Ö., 2007b. Business model analysis for local access provisioning. IEEE 18th International Symposium on Personal, Indoor and Mobile Radio Communications.

Markoff, J., 2008, 25 May. Global dreams for a wireless web. New York Times.

Meinrath, S. D., Calabrese, M., 2008. Policy backgrounder: Unlicensed "White space device" Operations on the TV band and the myth of harmful interference. New America Foundation Wireless Future Program, Washington, DC. http://www.newamerica.net/files/WSDBackgrounder.pdf.

Middleton, C., Crow, B., 2008. Building Wi-Fi networks for communities: Three Canadian cases. Canadian Journal of Communication 33, 419-441.

Middleton, C., Longford, G., et al., 2006. ICT infrastructure as public infrastructure: Exploring the benefits of public wireless networks. Telecommunications Policy Research Conference, Arlington, VA.

Middleton, C. A., 2007. A framework for investigating the value of public wireless networks. Telecommunications Policy Research Conference, Arlington, VA.

muniwireless.com, 2006. List of bids issued by cities and counties in 2005 and 2006 (january 30 update). http://www.muniwireless.com/reports/docs/RFPs2005-2006.rtf. (accessed 4 September, 2006).

OECD Directorate for Science Technology and Industry, 2007. Participative web: User-created content. OECD, Paris.

Ohira, K., Huang, Y., et al., 2007. Loosely trusted yet secure roaming architecture for public 
wireless Internet service. Second International Conference on Informatics Research for Development of Knowledge Society Infrastructure.

Organisation for Economic Co-Operation and Development, 2010. OECD broadband subscriptions, by technology, June 2009.

http://www.oecd.org/dataoecd/11/20/39575781.xls. (accessed 29 March, 2010).

Otsuka, Y., 2009. Mobile broadband: Pricing and services. OECD Directorate for Science, Technology and Industry - Committee for Information, Computer and Communications Policy, Paris. http://www.oecd.org.ezproxy.lib.ryerson.ca/dataoecd/26/19/43280727.pdf. (accessed 26 July 2009).

Poulus, T., 2010. Oono shows small scale can work on FTTx market. http://www.telecompaper.com/news/article.aspx?cid=714364. (accessed 4 April, 2010).

Powell, A., 2008a. CWIRP case study map: Fred e-zone. Community Wireless Infrastructure Research Project, http://www.cwirp.ca/files/CWIRP_eZone_case.pdf. (accessed 24 April, 2009).

Powell, A., 2008b. Wifi publics - producing community and technology. Information, Communication \& Society 11, 1068 - 1088.

Powell, A., Meinrath, S. D., 2008. Wireless networking for communities, citizens, and the public interest: Global perspectives. Journal of Community Informatics 4.

Powell, A., Shade, L. R., 2006. Going Wi-Fi in Canada: Municipal, and community initiatives. Government Information Quarterly 23, 381-403.

Prime Minister of Australia, 2009. New national broadband network. http://www.minister.dbcde.gov.au/media/media_releases/2009/022. (accessed 10 April, 2009).

Puchol, M., 2006. The real FON statistics: Lies, manipulation or fantasy. http://tech.am/2006/09/25/the-real-fon-statistics-\%E2\%80\%93-lies-manipulation-orfantasy/. (accessed 31 May, 2008).

Rainie, L., Horrigan, J., 2005. A decade of adoption: How the internet has woven itself into American life. Pew Internet \& American Life Project, Washington, DC. http://www.pewinternet.org/ /media//Files/Reports/2005/Internet_Status_2005.pdf.pdf.

Reinhardt, A., 2006. 8 February. From hot spots to FON zones? Business Week Online.

Rideout, V. N., Reddick, A. J., 2005. Sustaining community access to technology: Who should pay and why. The Journal of Community Informatics 1, 45-62.

Sandvig, C., 2004. An initial assessment of cooperative action in Wi-Fi networking. Telecommunications Policy 28, 579-602. 
Sandvine, 2010. 2010 mobile Internet phenomena report. Sandvine, Waterloo. http://www.sandvine.com/news/global_broadband_trends.asp. (accessed 11 April 2010).

Sawhney, H., 1992. The public telephone network: Stages in infrastructure development. Telecommunications Policy 16, 538-552.

Sawhney, H., 2003. Wi-Fi networks and the rerun of the cycle. info 5, 25-33.

Schneier, B., 2008. 10 January. Steal this Wi-Fi. Wired.

Scott, B., Chesley, R. E., et al., 2005. Profiles of municipal and community broadband networks. Free Press, Northampton, MA. http://www.broadbandcity.gr/content/modules/downloads/Profiles_Of_Municipal_And_ Community_Broadband_Networks_(New_America_Foundation).pdf. (accessed 3 November 2008).

Shamp, S. A., 2004. Wi-Fi clouds and zones: A survey of municipal wireless initiatives. Mobile Media Consortium, University of Georgia.

Simon, N., 2005. Interview with martin varsavsky. http://blog.fon.com/en/archive/2005/11/. (accessed 31 May, 2008).

Su, C. H., Hwang, Y.-C., et al., 2008. A study on the willingness of using FON in the domain of wireless communication. Fourth International Conference on Networked Computing and Advanced Information Management.

Tallberg, M., 2006. P2P-based roaming between home WLAN hotspots. Helsinki University of Technology, Helsinki. http://www.netlab.tkk.fi/opetus/s383042/2006/papers_pdf/F1.pdf. (accessed 22 April, 2009).

Tapia, A. H., Powell, A., et al., 2009. Reforming policy to promote local broadband networks. Journal of Communication Inquiry 33, 354-375.

Thompson, N. A., Yin, Z., et al., 2007. Authentication on the edge: Distributed authentication for a global open wi-fi network. Paper presented at Proceedings of the 13th annual ACM international conference on mobile computing and networking, Montreal, Quebec, Canada.

Urbina, I., 2008, 22 March. Hopes for wireless cities fade as Internet providers pull out. New York Times.

Van Den Besselaar, P., 2005. Local information and communication infrastructures: An introduction. In Van Den Besselaar, P., Koizumi, S. (Eds.), Digital cities III. Springer, Berlin.

Varsavsky, M., 2008. FON latest figures. http://english.martinvarsavsky.net/general/fon-latestfigures.html. (accessed 31 March, 2009). 
Varsavsky, M., 2010. 2010: The year of WiFi, the year of FON.

http://english.martinvarsavsky.net/general/2010-the-year-of-wifi-the-year-of-fon.html. (accessed 8 April, 2010).

Veldhuijzen Van Zanten, B., 2008. FON raises \$9.5 million: No more free hardware? http://thenextweb.org/2008/04/12/fon-raises-95-million-no-more-free-hardware. (accessed 31 March, 2009).

Vos, E., 2007. Muniwireless.com: 1 August 2007 list of US cities and regions. http://muniwireless.com/reports/docs/Aug-1-2007summary.pdf. (accessed 25 August, 2007).

Vos, E., 2009. Muniwireless.com: 28 March 2009 list of US cities and regions. (accessed 28 March, 2009).

WiMAX Forum, 2005. Fixed, nomadic, portable and mobile applications for 802.16-2004 and 802.16e WiMAX networks

Wong, M., 2008. CWIRP case study map: Wireless nomad. Community Wireless Infrastructure Research Project, http://cwirp.ca/files/CWIRP_WirelessNomad_case.pdf. (accessed 24 April, 2009).

Wong, M., Clement, A., 2007. Sharing wireless Internet in urban neighbourhoods. In Steinfeld, C., Pentland, B. T., et al. (Eds.), Communities and technologies 2007: Proceedings of the third communities and technologies conference. Springer-Verlag, London.

Yao, J. J., Chen, H. H., 2007. Fixed-mobile convergence, streaming multimedia services, and peer-to-peer communication. In Sebe, N., Liu, Y., et al. (Eds.), Multimedia content analysis and mining Springer, Berlin. 